\title{
Considerations on the "Mutual Embedding" of Tibetan, Hui, Tu, Salar and Mongolian and Han Nationality in the Perspective of Intermarriage -Data Analysis Based on Qinghai Province
}

\author{
Shiliang Wang ${ }^{1, a}$ \\ ${ }^{1}$ Qinghai University, Qinghai, Xining, China, 810016
}

Keywords: Intermarriage, Qinghai, National Interlocking

\begin{abstract}
Intermarriage is an important part of the study of ethnic relations and it is also an important consideration for national interdependence. Taking the marriage registration data of six counties in Qinghai Province as an example, this paper tries to analyze the "interlocking" situation of the Tibetan, Hui, Tu, Salar and Mongolian and Han Nationality residents through the registration of marriage and registration of divorce of urban residents in the period from 1994 to 2015. This paper makes a judgment on the quality of ethnic relations and the degree of inter-ethnic integration of the main urban and rural residents in Qinghai Province.
\end{abstract}

\section{Introduction}

"In intermarriage studies in Europe and the United States, intermarriage is seen as a key measure of the quality of inter-ethnic relations and the integration of inter-ethnic societies." "The ratio of intermarriage among different groups is a measure of the society between people in any society Distance, the nature of contact between groups, the intensity of group identity, the relative size of the population, the heterogeneity of the population, and the social integration process." Gordon argues that only when the assimilation of ethnic groups reaches a high level, the size of the intermarriage is possible. Qinghai Province is a multi-ethnic province, living in the territory of the Han, there are 54 ethnic minorities, of which the Qinghai ethnic minorities mainly Tibetan, Hui, Tu, Salar and Mongolian. According to household statistics, by the end of 2013, the province's Han population of 306.34 million, accounting for $53.02 \%$ of the total population, ethnic minority population of 371.45 million accounting for $46.98 \%$ of the total population. Minority population is second only to Tibet, Xinjiang, higher than Inner Mongolia, Ningxia, Guangxi and other ethnic autonomous regions, ranking third in the country. Ethnic intermarriage is an important part of the study of ethnic relations, to a certain extent, national intermarriage is also "national interlocking" an important consideration.

According to the "Qinghai Civil Affairs Statistics Yearbook (2015)" data show that: the average number of married women in Qinghai Province from 2006 to 2010 is 31062 pairs (excluding foreign marriage), the average number of divorces is 3877 pairs, the average annual divorce rate of 12.5\% In 2014 the average number of marriages was 43670 pairs (excluding foreign marriages), with an average annual divorce of 6173 , with an average annual divorce rate of $13.0 \%$. It can be seen that the number of marriages and divorce rates have increased in Qinghai Province in the past decade. And whether there is any change in the development trend of national intermarriage? What are the characteristics of ethnic intermarriage? Do these intermarriage characteristics reflect the "interlocking" status of the main ethnic groups in Qinghai Province? These are the main purpose of this paper. The article aims to use the research group to collect nearly 15 years of Qinghai Province, two counties and six counties urban resident's marriages, to understand these ethnic groups within the intermarriage and ethnic customs of the status quo, the main ethnic groups in Qinghai Province, "mutual This paper aims to judge the inter-ethnic relations of ethnic and urban residents in Qinghai Province and the degree of integration of inter-ethnic society. It is also a supplement to the research contents of ethnic groups in Qinghai province. 


\section{The Sample Analysis}

The research group has traveled to six counties in Qinghai Province in the first half of the year and the second half of 2016 (cities A, B, C, D, E, F, G and H, A and C respectively) Are the prefecture-level cities in Qinghai Province, B County, F County, G County and H County for the ethnic minority autonomous counties. Geographical location are located in the eastern part of Qinghai Province), the local civil marriage registration department, through the national marriage registration system to obtain these areas 1994- The basic data of the marriage registration in 2015 (excluding the registration of personal information, and are registered for the registration of urban residents), after finishing statistics, delete non-ethnic marriage samples, and ultimately left a national marriage involving 34325 marriage registration samples And 6952 divorce registration samples, this paper mainly to these marriage registration samples to reflect the Qinghai Province in the past 15 years of ethnic marriages.

During the period from 1994 to 2015, the marriage registration and divorce registration of ethnic marriages in the six counties of the two cities were accounted for $60.5 \%$ of the total civil intercourse, while $\mathrm{C}$ city and the remaining six counties accounted for $39.5 \%$ of the total marriages. According to the sixth census data, the total population of the two cities and six counties accounted for $66.6 \%$ of the total population of Qinghai Province, Qinghai Province and sparsely populated, for urban residents' intermarriage study, the two cities and six counties have a certain Representative. During the period from 1994 to 2015, the situation of ethnic intermarriage in the six counties of the two cities was on the rise. Among them, intermarriage and intermarriage between 1994 and 1999 showed a relatively stable trend, and there was a low level in 2001, - there was an upward trend in 2006, and the growth trend between 2007 and 2015 was more rapid than the previous two stages, indicating that ethnic marriages after 2006 were more common and, to a certain extent, After the development of the western region, the rising trend of marriage (whether marriage registration or divorce registration) is more obvious, also shows that the nation is embedded on a deeper layer.

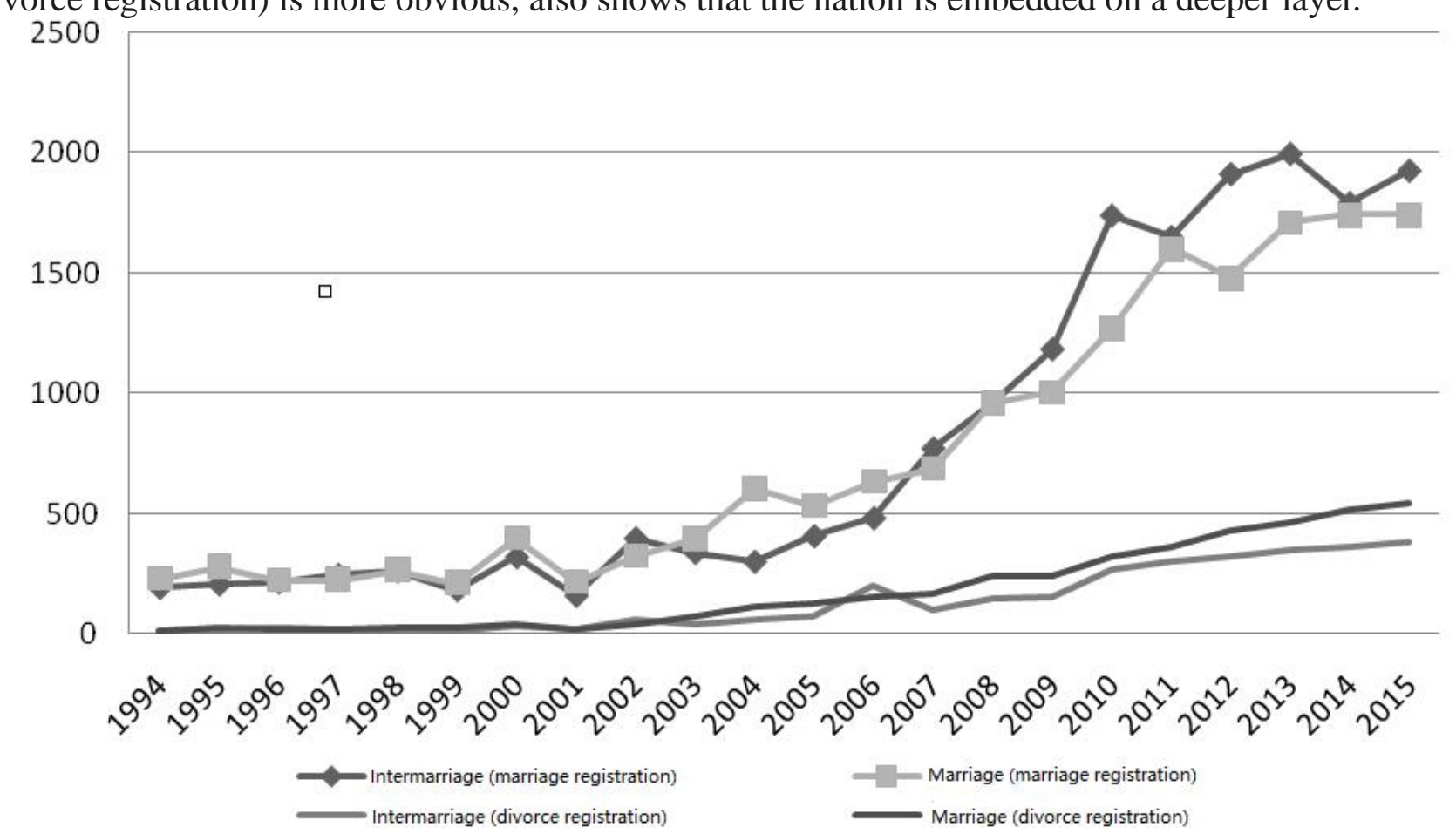

Figure 1 Qinghai Province two counties and six counties marriages (1994 - 2015)

Qinghai Province, the main living of the six ethnic customs of the basic situation, the specific analysis can be the following conclusions:

Hui. The Hui nationality is divided into the living area of the whole country, widely distributed in the whole area, and scattered to the whole, and specifically to the local, the mosque as the center to form a small centralized Hui community, Qinghai Hui religious characteristics is the basic 
religious beliefs. According to the sample of marriage registration, the intermarriage of the Hui people (13772 pairs) and marriages (2447 pairs) accounted for $84.9 \%$ and $15.1 \%$ of the total marriages of the Hui nationality in the sample respectively, which indicated that the Hui nationality paid more attention to the intermarriage This is mainly due to "in the history of the Hui, whether it is the ancestors of the Arab, Persian 'fan', or yuan, after the Hui community to join the community of Han, Mongolian, Tibetan and other nationalities, the prerequisite is' Back to ', that is, first become a Muslim, and then can become a member of the Hui community, which of course is the development and expansion of the Hui in the process of an unwritten rule, it is not the slightest coercive nature, depends entirely on the other's voluntary. "In the Hui Among the 2869 divorce cases, divorce (2204 pairs) accounted for $76.8 \%$, divorce (665 pairs) accounted for $23.2 \%$. Among the other five ethnic groups, the Han nationality (3617), the Salar (782), the Dongxiang (147), the Tibetan (139) and the Tu (51) Three ethnic groups and the marriage of the Hui, accounting for 93\% of the marriage outside the tribe, while the Salar and Dongxiang are beliefs of Islam.

Han Nationality. Qinghai folk belief is original from the original witch religion, in the future development, continue to absorb the surrounding culture, its content is increasingly complex, in today there is still some vitality. The religious beliefs of Qinghai Han nationality are Han Buddhism, Tibetan Buddhism, Taoism, Christianity and so on. According to the statistics of marriage registration, the Han nationality marriages are (8131 pairs), divorce are (1918 pairs). Among the other marriages in the marriage, the other five ethnic groups marriages were Tibetan (4287), Hui, Tu (3013), Mongolian (1576) and Manchu (1277), the first three ethnic groups and the Han nationality Intermarriage, accounting for $74.4 \%$ of the Han ethnic marriage.

Tibetan. Tibetan Buddhism has great influence on Qinghai Tibetan. According to the registration data of the marriage, the Tibetan intermarriage (1983) and the intermarriage (2179 pairs) accounted for $47.6 \%$ and $52.4 \%$ of the total number of Tibetan marriages in the sample, which were nearly 5 percentage points, which indicated that the Tibetan intermarriage There is a gap between marriage and marriage. This feature also exists in the Tibetan divorce registration sample, $46.5 \%$ and $53.5 \%$ of the total number of divorce cases (463 pairs) and divorce (532 pairs) respectively. Among the top five other marriages, the Han nationality, the Mongolian (253), the Tu (275), the Hui and the Manchu (45), the first three ethnic groups and the Tibetan marriages, Tibetan ethnic marriage is 95.4\%.

Tu. "Qinghai Tu people believe in Tibetan Buddhism Gelug Sect, in addition, there are some people in the belief in Tibetan Buddhism, but also believes in Taoism."

According to the marriage registration data, the Tu nationality intermarriage (330 pairs), marriages (1504 pairs), respectively, accounted for $18 \%$ and $82 \%$ of the total number of Turkish national marriages, indicating that the Tu people more inclined to (59 pairs) and divorce (273 pairs), accounting for $17.8 \%$ and $82.2 \%$ of the divorce cases of the Tu nationality, respectively. Among the top five other marriages, the Han, Tibetan, Mongolian (57), Hui and Manchu (22), the first three ethnic groups and the Turkish people marriages of the $97.3 \%$.

Salar. Salar is one of the peoples of Islam in China, "belongs to the Sunnis, but then the various sects have spread in the Salaram, there have been the end of the head, Ichwani and China Sufism four University of the tiger non - yeah, Ga Di Lin Ye, Zhe Lin Ye Ye and other gate and tribe.

According to the marriage registration data, the Salar tribe intermarriage (1258 pairs), marriages (423 pairs) accounted for salarat marriages of the total number of $74.8 \%$ and $25.2 \%$, indicating that the Salar also has a high degree of emphasis on intermarriage The tradition. Divorce (138 pairs) and marriages (85 pairs) accounted for $38.1 \%$ and $61.9 \%$ of Salar divorce respectively. Among the top five other marriages, the Hui, Han (177), Tibetan (12), Dongxiang (5) and Uygur (1), the first three ethnic groups Salar marriages accounted for 98.5 per cent of the Mara tribe.

Mongolian. "Mongolian Mongolian early faith shamanism, Mongolian and Tibetan Buddhism after the Yuan Dynasty contact, and believe in Tibetan Buddhism."

According to the marriage registration data, the Mongolian ethnic intermarriage (227 pairs) and marriages (858 pairs) accounted for $20.9 \%$ and $79.1 \%$ of the total number of Mongolian ethnic marriages in the sample respectively. Divorce (60 pairs) and divorce (212 pairs) accounted for 
22.1\% and 79.9\% of Mongolian divorce cases, respectively. Among the top five other marriages, the Han, Tibetan, Tu, Hui and Manchu (20), the first three ethnic groups and the Mongolian marriage, accounted for the Mongolian family marriage $96.1 \%$.

Qinghai Province, the other ethnic minorities are Dongxiang, security, Miao, Yao, etc., the population in the province's total population accounted for a small proportion of intermarriage (37 pairs) and marriages (1176 pairs) accounted for samples The total number of $3.1 \%$ and $96.9 \%$, marriages and marriages with the Han majority. This suggests that intermarriage in other ethnic minorities is more common. Divorce, divorce (333 pairs) and divorce (10 pairs) accounted for $97.1 \%$ and $2.9 \%$ of divorce cases, respectively.

\section{The Basic Conclusions}

In general, the Tibetan soil and the Han nationality belong to different religious beliefs, living customs and cultural traditions. Six ethnic groups: Tibetan, Tu and Mongolian almost all people believe in Tibetan Buddhism, Hui, Sala, Kazak almost all people believe in Islam. Christianity is mainly Han. In addition the Han people also believe in Chinese Buddhism, Taoism, Catholicism. In other words, known as the world's three major religions of Buddhism, Islam, Christianity in the province have spread, the existing temple of nearly 2,000 temples, of which the influence of Tibetan Buddhism and Islam greater. From the above marriage registration sample analysis shows that, in general, the main ethnic groups in Qinghai Province, "interlocking" situation is more harmonious. The author thinks that the main urbanization construction promotes the social movement of all ethnic groups. In the macro aspect, the urbanization is the fundamental change of the social and economic activities. It is the process of the transformation from the agricultural society to the industrial society and the information society. , Urbanization is essentially the main body (in terms of Qinghai Province, mainly refers to the farmers and herdsmen) to the town of the transfer process. It includes the transformation of the economic activities of farmers and herdsmen from agriculture and animal husbandry activities to non-agriculture and animal husbandry industry, the change of life style from rural singleness to urban life, and the way of cultural activities, way of thinking, various values The change of concept and re-socialization, etc., which includes changes in the concept of marriage, changes in the concept of marriage in the urbanization of the promotion also promoted the main ethnic groups in Qinghai Province ethnic and intercultural integration increased significantly.

\section{Acknowledgements}

Fund Project: National Social Science Fund Project (Status and Construction Path of National Interlocking Community in Qinghai Province in the Process of New Urbanization, Item No: 15BSH117)

\section{References}

[1] Qinghai Province Local Records Compilation Committee. Qinghai Province, the Ethnography [M]. Beijing: National Publishing House, 2008, 235.

[2] Qinghai Provincial Local Chronicles Compilation Committee. Qinghai Province, Ethnography [M]. Beijing: National Press, 2008, 312.

[3] Qinghai Province Local Records Compilation Committee. Qinghai Province, the Ethnography [M]. Beijing: National Publishing House, 2008, 369.

[4] Qinghai Province Local Chronicles Compilation Committee. Qinghai Province Ethnography [M]. Beijing: National Publishing House, 2008, 411. 